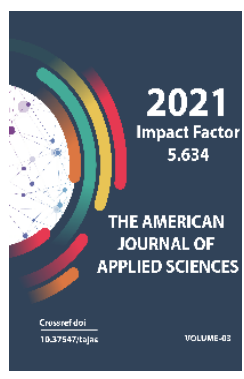

\title{
The Role Of Laboratory Classes In Teaching A Physics Course In High School
}

Karimova Muhayyo Usmonovna

Student Of Bukhara State University, Bukhara, Uzbekistan

Journal Website:

https://theamericanjou

rnals.com/index.php/ta

jas

Copyright: Original

content from this work

may be used under the

terms of the creative

commons attributes

4.0 licence.

\section{ABSTRACT}

This article describes the methodology for organizing laboratory classes in the subject of physics on the basis of the state Program in the subject. This technique can be used by teachers in teaching the subject of physics, students and students interested in physics. It is recommended as a practical and methodological indication for young teachers when organizing independent work of students in groups and individually, using modern information and pedagogical technologies in the educational process.

\section{KEYWORDS}

Model of physical education, development, pedagogical tendencies, educational process, pedagogy, teaching, teaching methods, general education, humanitarian, laboratory work, physics and mathematics, technical, experimental training, educational process, learning efficiency, practical skills.

\section{INTRODUCTION}

Modern trends in the development of school education are due to the introduction of the ideas of personality-oriented pedagogy into the educational process. The individual nature of the development of each student in accordance with his abilities, inclinations and interests allows for differentiated teaching. The issue of the introduction of modern pedagogical technologies, the use of innovative ideas in the educational process is gaining popularity. For this reason, one of the most pressing problems is distinguishing between known methods and explaining them correctly 


\section{MAIN PART}

The existing model of physical education in secondary school is substantiated by the teaching of theoretical knowledge, practical training and laboratory work. Let's look at the example of the content of the laboratory work.

\section{Laboratory work № 1}

Topic: The study of the motion of an object tilted to the horizon.

Objective: To check that the flight distance of an object depends on the angle of shooting.

Tools and equipment: Ballistic pistol, metal balloon, measuring tape, 2-3 sheets of white and black paper.

Basic formulas:

$L=\frac{V_{0}^{2} \sin 2 \alpha}{g}$

$h_{\max }=\frac{V_{0}^{2} \sin ^{2} \alpha}{2 g}$

$t_{u}=\frac{2 V_{0} \sin \alpha}{g}$

$V_{0}=\sqrt{g l / \sin 2 \alpha}$

The order of work:

1. The ballistic pistol is mounted on the edge of the laboratory table.
2. The angle of inclination of the ballistic pistol is fixed to the handle by 300 (the angle of inclination is determined by means of transport attached to the pistol).

3. Pull through the handle and insert into the barrel hook.

4. A metal ball is placed inside the barrel.

5. The handle is removed from the hook and the place where the balloon falls is fixed.

6. White paper and black copy paper are put together where the balloon falls.

7. It is held by the handle and inserted into the table hook.

8. A metal balloon is placed inside the table.

9. The catch is released from the hook and the place where the balloon falls is observed.

10. The experiment is repeated at least 3 times, as mentioned above.

11. Remove the black copy of the white paper without moving it. The balloon's flight distance is measured by replacing the marks left on the white paper.

12. Repeat the experiment in the order shown above, changing the angle of inclination (400, 600 ....).

13. Calculate the measurement error based on the results obtained.

14. According to the average flight distance, the velocity of the balloon is calculated using the expression (4).

15. Using the result of the calculation, the flight time of the balloon is calculated according to expression (3).

16. The values of the calculated quantities are recorded in the following table. 
Table 1. Values of calculated quantities

\begin{tabular}{|c|c|c|c|c|c|c|c|c|}
\hline $\begin{array}{c}\text { Shooting } \\
\text { angle }\end{array}$ & № & $\begin{array}{l}\text { I, flight } \\
\text { distance } \\
\text { (m) }\end{array}$ & $\begin{array}{c}\text { I } \\
(\mathrm{m})\end{array}$ & $\begin{array}{c}\Delta \mathrm{l} \\
(\mathrm{m})\end{array}$ & $\begin{array}{c}\Delta \mathrm{l} \\
(\mathrm{m})\end{array}$ & $\varepsilon=\frac{\Delta l}{l} \cdot 100 \%$ & $\begin{array}{l}\mathrm{V}^{0} \\
\mathrm{~m} / \mathrm{s}\end{array}$ & $\begin{array}{l}t_{0} \\
s\end{array}$ \\
\hline $30^{\circ}$ & $\begin{array}{l}\text { 1st shot } \\
2 \text { nd shot } \\
3 \text { shots }\end{array}$ & $\begin{array}{c}85 \\
105 \\
102\end{array}$ & 97 & $\begin{array}{l}12 \\
8 \\
5\end{array}$ & 8,3 & 8,5 & 33,7 & 3,37 \\
\hline $45^{\circ}$ & $\begin{array}{l}\text { 1st shot } \\
\text { 2nd shot } \\
3 \text { shots }\end{array}$ & $\begin{array}{l}125 \\
123 \\
112\end{array}$ & 120 & $\begin{array}{l}5 \\
3 \\
8\end{array}$ & 5,3 & 4,4 & 34,6 & 4,8 \\
\hline $60^{\circ}$ & $\begin{array}{l}\text { 1st shot } \\
\text { 2nd shot } \\
3 \text { shots }\end{array}$ & $\begin{array}{l}72 \\
71 \\
76\end{array}$ & 73 & $\begin{array}{l}1 \\
2 \\
3\end{array}$ & 2 & 2,7 & 30 & 5 \\
\hline
\end{tabular}

Control questions:

1. What is the trajectory of an object tilted relative to the horizon?

2. What is the magnitude of the flight distance of an object tilted relative to the horizon?
3. Analyze that the value of flight distance and flight time depends on the angle of shooting according to the results obtained in the experiment.

4. $V_{0}$ what is the velocity of the object shot at the initial velocity at the time of descent, and what is the angle with the horizon?

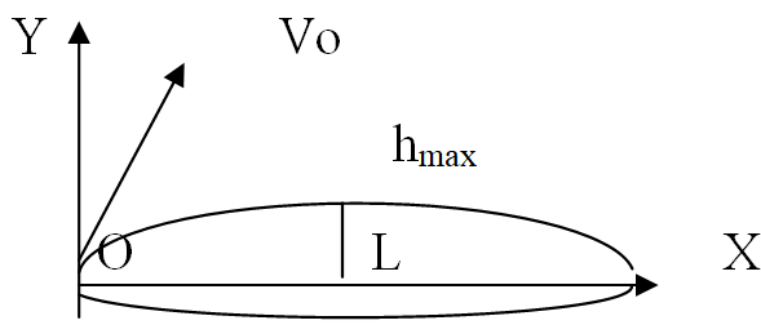

Fifure 1. Angle and flight distance changes.

Conclusion: We used a ballistic pistol to determine the dependence of the flight distance of an object on the size of the angle. So when the angle changes, the flight distance changes.

\section{Laboratory work №2}

Topic: Determining the acceleration of free fall using a mathematical pendulum.
Objective: To teach students to determine the acceleration of free fall using a mathematical pendulum.

Required tools: Instant meter, measuring tape, balloon, thread.

Introduction: A mathematical pendulum is a material point that hangs on a long string that is weightless and does not stretch, and can 
move under the influence of gravity. A smaller, heavier ball hanging from a long thin rope can be a mathematical pendulum. The deflection of the pendulum from the equilibrium position can be characterized by the angle formed by the vertical line of the thread. When the pendulum is in equilibrium, the tensile force of the rope is balanced by the gravitational force $\mathrm{pq}_{\mathrm{mg}}$ applied to the material point.

If the pendulum is tilted at a certain angle, the tension of the rope is balanced by the force of gravity. The gravitational force acts as a repulsive force and causes vibrations. When the angle is small, it can be assumed that $B C$ coincides with $B C B C$, which is equal to the displacement of the arc $h$. using the similarity of the dashed triangles, let's determine the magnitude of the repulsive force. Given that the repulsive force is always directed in the opposite direction to the displacement, we can write the formula as follows:

$$
F=-k x
$$

This means that the vibrations of a mathematical pendulum tilted at a small angle from the state of equilibrium under the influence of gravity will be hormonal oscillations. Therefore, the force of gravity can be called a quasi-elastic force. From the formulas, the oscillations of the mathematical pendulum are related to the frequency as follows:

$T=2 \sqrt{\frac{l}{g}}$

1. The order of business

2. Hang a string balloon on a tripod

3. Turn the balloon $5-8 \mathrm{~cm}$ from the equilibrium position and burn it

4. Measure the length of the pendulum.

5. We measure the time taken for the vibration.

6. Repeat these measurements 3 times.

7. $\mathrm{G}_{\text {mid }} \mathrm{q} 4 \underline{\square}$

8. We record the results in a table

Results of the work:

Table 2. The results of the work

\begin{tabular}{|c|c|c|c|c|c|c|}
\hline $\mathrm{T} / \mathrm{r}$ & $\mathrm{L}, \mathrm{m}$ & $\mathrm{N}$ & $\mathrm{T}, \mathrm{s}$ & To'rt, sek & To'rt & Go'rt \\
\hline 1 & $1 \mathrm{~m}$ & 40 & 79 & 80 & 2 & \\
\hline 2 & $1 \mathrm{~m}$ & 40 & 80 & 80 & 2 & 9,85 \\
\hline 3 & $1 \mathrm{~m}$ & 40 & 80 & 80 & 2 & \\
\hline
\end{tabular}

\section{CONCLUSION}

We determined the oscillation period of the pendulum, calculated the acceleration of free fall from the pendulum oscillation formula, repeated the experiments 3 times. We found that the results obtained were close to each other.

\section{REFERENCES}

1. Kakhkhorov, S. K., Juraev, H. O., \& Atoeva, M. F. (2019). Use of alternative energy sources at the natural sciences lessons. The Way of Science, 36(2), 148-150.

2. Khusniddin, J. (2018). Ways of using educational materials on alternative 
energy sources at natural lessons. European science review, (1-2).

3. Oltinboyevich, J. K. (2015). Training materials on sources the alternative energy in integration of natural sciences. Humanities and Social Sciences in Europe: Achievements and Perspectives, 32.

4. Qahhorov, S. Q., Samiev, K. A., \& Jo'raev, H. O. (2014). Process modeling in solar devices. Monograph. Tashkent. ITAPRESS.

5. Muhiddinovna, B. Z. (2020). Functions and forms of chemical experiment. European science review, (1-2).

6. Atoyeva, M. F. Pedagogical Tests As An Element Of Types of Pedagogical Technologies. The American Journal of Applied Sciences, 2(09), 2689-09.

7. Farkhodovna, A. M. (2020). The problems of preparing students for the use of school physical experiment in the context of specialized education at secondary schools. European Journal of Research and Reflection in Educational Sciences Vol, 8(9).

8. Abdullozizovna, V. K. (2020). The National Intelligentsia Of The Late XIX-Early XX Centuries: On The Work Of Is' hakhon Ibrat" Mezon Ul-Zamon". The American Journal of Applied sciences, 2(08), 100-108.

9. Farhodovna, A. M., Olimboevich, A. J., \& Badriddinovich, K. B. (2020). Innovative Pedogogical Technologies For Training The Course of Physics. The American Journal of Interdisciplinary Innovations and Research, 2(12), 82-91.
10. Atoyeva, M. F. (2016). The significance of periodicity at teaching physics. The Way of Science. Volgograd, 10(32), 62-64.

11. Atoyeva, M. F. (2016). Interdisciplinary relations in physics course at specialized secondary education. The Way of Science. Volgograd, 9(31), 22-24.

12. Atoeva, M. F. (2020). Didactic foundations of inter-media relations in the training of university students. Theoretical \& Applied Science, (6), 124-126.

13. Cacheiro-Gonzalez, M. L., Medina-Rivilla, A., Dominguez-Garrido, M. C., \& MedinaDominguez, M. (2019). The learning platform in distance higher education: Student's perceptions. Turkish Online Journal of Distance Education, 20(1), 71-95.

14. Kosimov, L., \& Kosimova, S. (2021). Optimization of the composition of dry slag-alkaline mixtures. Збірник наукових праць ^ózoб.

15. Djuraeva, D. D., \& Berdiyeva, Z. M. (2016). Cultural heritage as a factor of human development (on the example of Uzbekistan). Ученый XXI века, 23. 